Relations industrielles

Industrial Relations

\title{
Issues in Business and Society : Reading and Cases, by William T. Greenwood, Houghton Mifflin Company, Boston, 1964, 554 pages.
}

\section{Bertrand Belzile}

Volume 20, numéro 1, 1965

URI : https://id.erudit.org/iderudit/027554ar

DOI : https://doi.org/10.7202/027554ar

Aller au sommaire du numéro

Éditeur(s)

Département des relations industrielles de l'Université Laval

ISSN

0034-379X (imprimé)

1703-8138 (numérique)

Découvrir la revue

Citer ce compte rendu

Belzile, B. (1965). Compte rendu de [Issues in Business and Society : Reading and Cases, by William T. Greenwood, Houghton Mifflin Company, Boston, 1964, 554 pages.] Relations industrielles / Industrial Relations, 20(1), 195-195.

https://doi.org/10.7202/027554ar

Tous droits réservés @ Département des relations industrielles de l'Université Laval, 1965
Ce document est protégé par la loi sur le droit d'auteur. L'utilisation des services d’Érudit (y compris la reproduction) est assujettie à sa politique d'utilisation que vous pouvez consulter en ligne.

https://apropos.erudit.org/fr/usagers/politique-dutilisation/ 
En oppendice l'auteur présent des cas de discussions dont l'utilisaton est focilitée por l'e Instructor's Manual , qui acompagne cet ouvroge. On trouve oussi en appendice deux exemples concrets tirés des situations types. sont appliqués les principes exposés dans les chapitres précédents.

Cet ouvroge est de lecture et de compréhension fociles, en effet les principes et énoncés théoriques sont illustrés par des exemples concrets tirées des situations types. II s'agit donc d'un d'un ensemble de recettes et de règles qui ne peuvent être ignorées de ceux qui sont appelés d̀ travailler en comité. Ce monuel toutefois s'ovèrera surtout utile pour ceux qui n'ont aucune expérience des groupes de discussions, une lecture ropide de cet ouvroge suffirait d combler cette locune, car on trouve ici un ensemble de connaissonces utiles, facilement et rapidement accessibles.

\section{Jean MICHAUD}

Issues in Business and Society : Reading and Coses, by William T. Greenwood, Houghton Mifflin Company, Boston, 1964, 554 pages.

Cet excellent ouvroge n'apportera rien de nouveou à quelques lecteurs très au fait du sujet discuté. En effet, comme son titre l'annonce, il comprend une collection d'articles et de cas traitant chacun à son point de vue le thème très vaste de l'entreprise, des offaires et la société. Même pour les lecteurs privilégiés dont nous venons de parler, chaque article déjà lu isolément prendro peut-être un sens nouveau, plus riche et plus significatif, en tant que partie logique d'un ensemble cohérent.

Aux autres personnes intéressées, ces lectures offriront une matière substantielle, diversifiée et étendue propre d̀ les foire réfléchir sur les principoux points de vue des relotions entre l'entreprise et la société. Le thème général est onalysé en dix-neuf sujets différents dont, d'oprès $M$. Greenwood lui-même les deux-tiers sont controversés et l'autre tiers présente des tendances nouvelles, en oppostion ovec les protiques classiques traditionnelles des affaires.

Dans une première partie portant sur notre société de l'entreprise privée, nous pouvons lire des opinions évoluées et justes, d̀ notre ovis, concernant le copitolisme et lo liberté, l'entreprise, lo concurrence et le gouvernement, puis finalement le rôle des profits.
En deuxième et troisième lieu, $M$. Greenwood a sélectionné des articles traitant de l'entreprise et ses publics, et ensuite de l'entreprise et l'individu dans la société.

L'outre partie comprend des articles qui intéresseront tout particulièrement la plupart des lecteurs de cette Revue. II s'agit en effet des relations patronales-ouvrières; on $y$ porle de convention collective, de responsabités des dirigeants vis-à-vis l'emploi (pleinemploi et chômoge), et enfin des justes pratiques d'emploi.

Des orticles et des cas sur l'éthique, lo religion et l'entreprise forment la cinquième partie. Dans la suivante, on peut y lire d'excellents articles, entre autres, de Neil Chomberlain, Jomes K. Dent et Peter F. Drucker, où l'on essaie de dégoger les tendances vers une philosophie de la direction. Une dernière partie traite des responsobilités sociales dans l'entreprise.

Certes, les lecteurs de cet ouvrage ne seront pas tous d'accord avec $M$. Greenwood sur le choix des articles et des cas. Le caractères plus ou moins controversé des sujets traités, donne à la sélection une importance particulièrement significotive, car elle doit se faire parmi des tendances souvent diamétralement opposées. On peut finir en disant qu'une allure progressiste se dégage de cette excellente sélection d'articles et de cos, qui est certes susceptible d'intéresser un grand nombre de lecteurs.

\section{Bertrand BELZILE}

Emploi en France, par Henri Hatzfeld et Jocques Freyssinet, dans la Collection a Economie et Humanisme ", les Editions Ouvrières, Paris, 1964, 271 pages.

Considérant que l'emploi est ò l'origine de nombreux et grands conflits contemporains, les auteurs ont voulu présenter un livre de vulgarisation sur la situation octuelle dans leur pays, ainsi que sur certains problèmes connexes, comme la formation professionnelle, migration régionales, exode rurale et quelques autres. Ce présent ouvrage ne prétend pas aider les spécialistes de la question, mais il entend servir les travailleurs eux-mêmes et les étudionts intéressés à l'emplois en Fronce

L'ouvrage se divise en trois parties. Dans la première, sous le titre I'Equilibre Global de I'Emploi, les auteurs envisagent le chômage et le plein emploi au double aspect de la pensée économique et de l'expérience his- 